\title{
DRY EYE- PREVALENCE AND ATTRIBUTABLE RISK FACTORS IN A HOSPITAL-BASED POPULATION
}

\author{
Kumaran Muniswamy1, Purnananda Mishra², Sampath Manavalan ${ }^{3}$
}

1 Postgraduate Student, Department of Ophthalmology, Rajah Muthiah Medical College, Chidambaram.

2 Professor and HOD, Department of Ophthalmology, Rajah Muthiah Medical College, Chidambaram.

3Professor, Department of Ophthalmology, Rajah Muthiah Medical College, Chidambaram.

\section{BACKGROUND}

ABSTRACT

Dry eye is a multifactorial disease of the tears and ocular surface that results in symptoms of discomfort, visual disturbance and tear film instability with potential damage to the ocular surface.

The aim is to study the prevalence of dry eye and evaluate various risk factors attributable to dry eye in a hospital-based population.

\section{MATERIALS AND METHODS}

A hospital-based population study was performed. In this cross-sectional study, 150 patients above 20 years of age of either sex, presenting with various ophthalmic complaints, were screened for dry eye who presented to the Department of Ophthalmology, Rajah Muthiah Medical College and Hospital, Annamalai Nagar, Chidambaram, between May 2015 and November 2017. Patients were included based on a standardised validated dry eye questionnaire, underwent various tests including tear breakup time (TBUT), Schirmer's test, Rose Bengal staining and presence of strands and/or filaments in either/both eyes.

\section{RESULTS}

The prevalence of dry eye was $16 \%$. It was significantly higher in males (16.4\%) than in females (15.5\%). Dry eye prevalence was maximum in those above 60 years of age (36.4\%) followed by the age group 41-60 years (17.9\%). Those with other refractive conditions constituted $46.67 \%$, emmetropia $34 \%$, myopia $8 \%$, hypermetropia $6 \%$ and astigmatism 5.33\%.

\section{CONCLUSION}

Dry eye is an underdiagnosed ocular disorder. The multifactorial aetiopathogenesis explains by itself why the clinical diagnosis of dry eye remains a challenge. Reduction in modifiable risk factors of dry eye is essential to reduce its prevalence.

\section{KEYWORDS}

Dry Eye, Tear Film Break-Up Time, Schirmer's Test, Rose Bengal Staining, Dry Eye Questionnaire.

HOW TO CITE THIS ARTICLE: Muniswamy K, Mishra P, Manavalan S. Dry eye- Prevalence and attributable risk factors in a hospitalbased population. J. Evolution Med. Dent. Sci. 2017;6(95):6987-6989, DOI: 10.14260/jemds/2017/1516

\section{BACKGROUND}

Dry eye is a multifactorial disease of the tears and ocular surface that results in symptoms of discomfort, visual disturbance and tear film instability with potential damage to the ocular surface. It is accompanied by increased osmolarity of the tear film and inflammation of the ocular surface. ${ }^{1}$ The prevalence of dry eyes varies from $10.5 \%$ to $66.6 \%$, thereby exhibiting wide range of disparity. ${ }^{2-4}$ Much of this difference arises from the fact that there is no standardisation of the types of patients selected for the study, dry eye questionnaires, objective tests and dry eye diagnostic criteria. Our aim was to determine dry eye prevalence, evaluate risk factors attributable to dry eye in a hospital-based population.

\section{MATERIALS AND METHODS}

In this cross-sectional study, 150 patients above 20 years of age presenting to the Department of Ophthalmology, Rajah

'Financial or Other Competing Interest': None.

Submission 27-11-2017, Peer Review 10-12-2017,

Acceptance 12-12-2017, Published 23-12-2017.

Corresponding Author:

Dr. Sampath Manavalan,

Professor

Department of Ophthalmology,

Rajah Muthiah Medical College, Chidambaram.

E-mail: kumaranmuniswamy@gmail.com

DOI: $10.14260 /$ jemds $/ 2017 / 1516$
Muthiah Medical College and Hospital, Annamalai Nagar, Chidambaram, between May 2015 and November 2017 were screened for dry eye. The patients were selected randomly and informed about the nature of the study. Patients suffering from acute ocular infections with extensive corneal or conjunctival pathology, contact lens users and those who had undergone extraocular or intraocular surgery within six months of the screening were excluded.

A general (history of systemic diseases pertaining to dry eye) and ophthalmic history, along with patient details, was elicited. Informed consent was obtained from subjects recruited for the study. A validated thirteen-item questionnaire suggested by T. Hikichi A. Yoshida et al. ${ }^{5}$ in which symptoms relating to dry eye was used: ocular fatigue, watering, foreign body sensation, non-sticky discharge, heavy sensation, dry sensation, discomfort, ocular pain, watering, temporary blurring of vision (improved on blinking), itching, redness, photophobia and burning sensation. A positive response is noted when the patient had that symptom occasionally, often or all the time, and negative response when the symptom occurs rarely or never. The total symptom score was calculated. Exposure to sunlight/high temperature, excessive wind, air pollution, smoking and drugs was enquired.

A brief systemic and ocular examination was carried out. Ocular examination included recording visual acuity, condition of lids and lid margins for irregularity, infection, tear 
meniscus height, tear film debris, conjunctiva and corneal surface for superficial punctate keratitis, strands, filamentary keratitis.

Objective tests (under room temperature conditions) included Rose Bengal staining, Schirmer's test and tear film breakup time (TBUT). Pre-cut strips for these tests were procured from a common source to ensure uniformity.

\section{The Criteria for Diagnosis of Dry Eye were}

- A symptom score of more than 3,

- Schirmer's test value of $<5 \mathrm{~mm}$ in 5 minutes,

- TBUT of $<10$ seconds,

- $\quad$ Rose Bengal staining score of $>3.5$,

- Presence of strands and/or filaments in either/both eyes.

If three or more of the above five tests were positive, the subject was deemed to be suffering from dry eye.

\section{Statistical Analysis}

All variables were registered in Excel worksheet (Microsoft Office 2007). All the subjects were evaluated at the baseline and after 3 years. The statistical analysis was carried out with SPSS Version 16.0 Software. All the data was presented as mean, standard deviation and percentage of efficacies. Chisquare test is used to evaluate the statistical significance. In this study, significant statistical difference has been accepted if the $P$ value is $<0.05$.

\section{RESULTS}

In the present study, dry eye prevalence was found on the rise with increase in age and is statistically significant $(\mathrm{p}<0.05)$.

\begin{tabular}{|c|c|c|}
\hline & $\begin{array}{c}\text { Number of } \\
\text { Subjects }\end{array}$ & Percentage \\
\hline \multicolumn{3}{|l|}{ Gender (in Years) } \\
\hline $21-40$ & 72 & 48.0 \\
\hline $41-60$ & 56 & 37.3 \\
\hline$>60$ & 22 & 14.7 \\
\hline \multicolumn{3}{|l|}{ Sex } \\
\hline Male & 72 & 48.0 \\
\hline Female & 78 & 52.0 \\
\hline \multicolumn{3}{|l|}{ Occupation } \\
\hline Farmer/Labourer & 35 & 23.3 \\
\hline $\begin{array}{l}\text { Others with high exposure } \\
\text { (Salesman, mechanic, } \\
\text { cook, driver, etc.) }\end{array}$ & 24 & 16.0 \\
\hline Homemaker, student & 79 & 52.7 \\
\hline $\begin{array}{c}\text { Others with low exposure } \\
\text { (Retired person, teacher, etc.) }\end{array}$ & 12 & 8.0 \\
\hline \multicolumn{3}{|c|}{ Table 1. Baseline Characteristics $(n=150)$} \\
\hline
\end{tabular}

The above Table 1 reveals baseline characteristics of study sample in the age group above 60 years $(14.7 \%)$. The next age group was $41-60$ (37.3\%) followed by $21-40$ years $(48.0 \%)$. Table 2 reveals the prevalence of dry eye in males (16.4\%) and females $(15.5 \%)$. The overall prevalence of dry eye is $16 \%$; $p$ $<0.05$, statistically significant.

\begin{tabular}{|c|c|c|c|c|}
\hline & $\begin{array}{c}\text { No. of } \\
\text { Subjects }\end{array}$ & $\begin{array}{c}\text { Dry eye } \\
\text { Subjects }\end{array}$ & $\begin{array}{c}\text { Prevalence } \\
\text { (\%) }\end{array}$ & P value \\
\hline $\begin{array}{c}\text { Gender } \\
\text { (in years) }\end{array}$ & & & & \\
\hline $21-40$ & 72 & 6 & 8.3 & \multirow{2}{*}{0.002} \\
\hline $41-60$ & 56 & 10 & 17.9 & \\
\hline$>60$ & 22 & 8 & 36.3 & \\
\cline { 1 - 4 } Sex & & & & \multirow{2}{*}{0.818} \\
\hline Male & 72 & 12 & 16.4 & 15.5 \\
\cline { 1 - 4 } Female & 78 & 13 & \multicolumn{2}{|l}{} \\
\cline { 1 - 4 } Table 2. Prevalence of Dry Eye According to Age and Sex \\
\hline
\end{tabular}

\begin{tabular}{|c|c|c|c|c|}
\hline & $\begin{array}{c}\text { No. of } \\
\text { Subjects }\end{array}$ & $\begin{array}{c}\text { Dry eye } \\
\text { Subjects }\end{array}$ & $\begin{array}{c}\text { Prevalence } \\
\text { (\%) }\end{array}$ & $\begin{array}{c}\text { P } \\
\text { value }\end{array}$ \\
\hline Occupation & & & & \\
\hline Farmer/Labourer & 35 & 6 & 17.1 & \\
\hline $\begin{array}{c}\text { Others with high } \\
\text { exposure } \\
\begin{array}{c}\text { (Salesman, mechanic, } \\
\text { cook, driver, etc.) }\end{array}\end{array}$ & 24 & 5 & 20.8 & \multirow{2}{*}{0.977} \\
\hline Homemaker, student & 79 & 10 & 12.6 & \\
\cline { 1 - 3 } $\begin{array}{c}\text { Others with low } \\
\text { exposure (Retired } \\
\text { person, teacher, etc.) }\end{array}$ & 12 & 3 & 25.0 & \\
\cline { 1 - 3 } Table 3. Prevalence of Dry Eye in Various Occupational \\
Groups
\end{tabular}

The above table illustrates the occupations of the study groups. Farmers/labourers showed a prevalence of $17.1 \%$; others with high exposure (salesman, mechanic, cook, driver, etc.) $20.8 \%$; homemakers and students $12.6 \%$ and those with low exposure (teacher, retired person, etc.), $25.0 \%(\mathrm{P}>0.05)$. Of these, the prevalence of dry eye was highest.

Postmenopausal woman showed dry eye prevalence of $7 / 30(23.3 \%)$ which is statistically not significant (OR=1.66).

Individuals like Mechanics, field workers and Salesman were the most affected with dry eye 5/24 (20.83\%), followed by farmers and labourers 6/35 (17.4\%). In our study population of 150 patients, the association of different occupations with prevalence of dry eye was not significant statistically.

Although exposure factors had a higher propensity of risk in developing dry eye like excessive wind, high temperature, sunlight, smoking and drug exposure, the prevalence of dry eye in this study was not significant $(\mathrm{OR}=1.53)$. Smokers had a prevalence of $2 / 9(22.22 \%)$, considered as a modifiable attributable risk factor.

Commonly used drugs were Antihistamines and bronchodilators, anti-allergic eye drops, anti-glaucoma eye drops, corticosteroid eye drops.

\section{DISCUSSION}

Out of 150 patients, our study revealed that the prevalence of dry eye was $16 \%$. In 2005, Sahai A and Mallik P6 in their study showed the prevalence to be $18.4 \%$, while a similar study about dry eye by Moss SE et al in $2000^{7}$ had an overall prevalence of $14.4 \%$.

In the present study, dry eye prevalence was found on the rise with increase in age and is statistically significant $(p<0.05)$. The study is consistent with the observation made by Moss SE et $\mathrm{al}^{7}$ and Lee $\mathrm{AJ}$ et al in $2002^{8}$ who reported significant increase in the prevalence of dry eye with increasing age $(\mathrm{p}<0.001)$. 
Although most studies reported an increased prevalence of dry eye in females than males, this study showed a higher prevalence among males (16.4\%). A study done in 2002 by Lee $\mathrm{AJ}$ et $\mathrm{al}^{8}$ found the prevalence to be 1.4 times higher for men than women. Likewise, Schein OD et al in $1997^{\circ}$ concluded the prevalence of dry eye was common in elderly, did not find an association between race and sex in their population-based study sample.

In our study population of 150 patients, the association of different occupations with prevalence of dry eye was not significant statistically. Occupations either in agricultural or within industrial areas were not associated with the risk of dry eye symptoms as similarly observed in 2002 by Lee $\mathrm{AJ}$ et al ${ }^{8}$ in their study.

None of the risk factors that may attribute to dry eye were found to be statistically significant in this study.

A similar study conducted in Indonesia by Lee $\mathrm{AJ}$ et al ${ }^{8}$ stated that increased sunlight exposure may increase the frequency of dry eye symptoms whereas the high humidity prevalent in the equatorial region could be protective.

In our study, the prevalence of dry eye in post-menopausal women was $23.3 \%$ which is statistically not significant $(\mathrm{OR}=1.66)$. Sahai A and Mallik P in their study in $2005^{6}$ also observed a prevalence of $22.8 \%$, almost correlating with the present study.

Among the study sample, patients with diabetes mellitus had a prevalence of $28.5 \%$ but were not significant (OR=2.46).

In our study, the prevalence of dry eye in patients on antihypertensive drugs was $36.3 \%$ but not significant $(\mathrm{OR}=3.4)$. A similar observation was made in 2000 by Moss SE et $\mathrm{al}^{7}$ that those using angiotensin-converting enzyme inhibitors had a lower incidence of dry eye whereas those patients using calcium channel blockers, the incidence was not statistically significant.

Smokers had a dry eye prevalence of $22.2 \%$ which is not significant (OR=1.54) in our study. In 2000, Moss SE et al ${ }^{7}$ also had similar observation in their study that smoking history was not associated with the incidence of dry eye.

In our study, the percentage with Schirmer 1 test $<5 \mathrm{~mm}$ was $85.71 \%$. Miki Uchino \& Murat Dogru ${ }^{10}$ et al in 2006 stated that Schirmer 1 test $<5 \mathrm{~mm}$ was $79.6 \%$. They concluded that the result of Schirmer 1 test is so variable that specific limit of normal tear production cannot be set for any group and statistical relation could not be established.

Schein OD et al11 in their study in 1997 concluded that a total of $11.3 \%$ (275/2432) of the population had a high Rose Bengal score for a prevalence of $2 \%$. In the present study, a total of $44.89 \%(22 / 150)$ had a score $>3$. In the present study, prevalence of dry eye with Rose Bengal score $>3.5$ was $14.6 \%$ which probably was the reason for the high percentage of dry eye with a score $>3.5$.

The disparity in the prevalence of dry eye may be due to lack of standardisation questionnaires of dry eye or the different dry eye diagnostic criteria employed. As our study is cross-sectional, it is possible only to demonstrate that a factor is associated with dry eye and not whether the particular factor precedes the dry eye. Finally, a larger sample could have been taken to study the prevalence of dry eye as it represents the entire population from which that sample is drawn.

\section{CONCLUSION}

Dry eye is one of the leading causes of ocular discomfort. In our study, dry eye prevalence increasing progressively with age showed a relative peak. Our study has shown higher prevalence in males as compared to females in the sample study. Exposure to excessive wind, sunlight and/or high temperature is significantly related to dry eye causation. Smoking is a modifiable risk factor in dry eye causation. The multifactorial aetiopathogenesis explains why the clinical diagnosis of dry eye remains a challenge, not only due to the wide spectrum of alterations of the ocular surface with different aetiology and pathophysiology but also due to the lack of well-standardised diagnostic test. By providing more emphasis on the importance of seeking professional help for symptoms of dry eye through public education, we can offer significant relief and perhaps, provide better quality of life.

\section{ACKNOWLEDGEMENT}

I am thankful to the Professor \& HOD, Department of Ophthalmology, Professors of the Department of Ophthalmology, Rajah Muthiah Medical College and copostgraduates for their inspiration to take up this study and they guided me through each and every step of this Research Work, by giving useful suggestions and made me complete this work successfully.

\section{REFERENCES}

[1] The definition and classification of dry eye disease: report of the Definition and Classification Subcommittee of the International Dry Eye WorkShop (2007). Ocul Surf 2007;5(2):75-92.

[2] Paulsen AJ, Cruickshanks KJ, Fischer ME, et al. Dry eye in the beaver dam offspring study: prevalence, risk factors, and health-related quality of life. Am J Ophthalmol 2014;157(4):799-806.

[3] Courtin R, Pereira B, Naughton G, et al. Prevalence of dry eye disease in visual display terminal workers: a systematic review and meta-analysis. BMJ 2016;6(1):e009675.

[4] Pujari MR, Salagar K, Bagare SN. Prevalence of dry eye in post-menopausal women. Journal of Evolution of Medical and Dental Sciences 2015;4(75):13005-10.

[5] Hikichi T, Yoshida A, Fukui Y, et al. Prevalence of dry eye in Japanese eye centers. Graefes Arch Clin Exp Ophthalmol 1995;233(9):555-8.

[6] Sahai A, Malik P. Dry eye: prevalence and attributable risk factors in a hospital-based population. Indian J Ophthalmol 2005;53(2):87-91.

[7] Moss SE, Klein R, Klein BE. Prevalence of and risk factors for dry eye syndrome. Arch Ophthalmol 2000;118(9):1264-8.

[8] Lee AJ, Saw SM, Gazzard G, et al. Prevalence and risk factors associated with dry eye symptoms: a population based study in Indonesia. $\mathrm{Br} \mathrm{J}$ Ophthalmol 2002;86(12):1347-51.

[9] Schein OD, Munoz B, Tielsch JM, et al. Prevalence of dry eye among the elderly. Am J Ophthalmol 1997;124(6):723-8.

[10] Uchino M, Dogru M, Yagi Y, et al. The features of dry eye disease in a Japanese elderly population. Optom Vis Sci 2006;83(11):797-802.

[11] Schein OD, Tielsch JM, Munoz B, et al. Relation between signs and symptoms of dry eye in the elderly. A population-based perspective. Ophthalmology 1997;104(9):1395-401. 